\title{
Evaluation of Depth of Cure and Knoop Hardness in a Dental Composite Photo-activated Using Different Methods
}

\author{
Andresa Carla OBICI \\ Mário Alexandre Coelho SINHORETI \\ Lourenço CORRER SOBRINHO \\ Mario Fernando de GOES \\ Simonides CONSANI \\ School of Dentistry of Piracicaba, UNICAMP, Piracicaba, SP, Brazil
}

\begin{abstract}
The aim of this study was to evaluate the depth of cure and Knoop hardness in the P60 composite resin photo-activated using different methods. A bipartite brass matrix ( $3 \mathrm{~mm}$ in diameter X $11 \mathrm{~mm}$ in height) was filled with the composite and photo-activation was performed using continuous light, exponential light, intermittent light, plasma arc curing (PAC) or light-emitting diodes (LED). After opening the matrix, the uncured material was removed with a steel spatula and the polymerized composite was measured using a pachymeter. The specimens were then included in self-curing acrylic resin and worn longitudinally and the hardness was measured on the surface and at depths of 1, 2, 3, 4 and $5 \mathrm{~mm}$. The data were analyzed by ANOVA and Tukey's test (5\%). The results showed that the depth of cure was higher with the intermittent light, followed by continuous light, exponential light, PAC and LED methods. Up to a depth of $2 \mathrm{~mm}$, all methods revealed similar hardness values, but there were differences between them at other depths, at which LED demonstrated the lowest values followed by PAC.
\end{abstract}

Key Words: photo-activation methods, composite resin, depth of cure, Knoop hardness, dental materials.

\section{INTRODUCTION}

The light-activated composite resins, brought into practice in the 1970 's, introduced expressive changes that made their satisfactory application in posterior teeth possible. However, characteristics such as composition, light intensity and exposure time can modify the final properties of the material and, thus, restrict the clinical applications. Type, size, quantity and refraction index of the fillers into composite exert an influence upon light transmission across the material and, consequently, the light attenuation and the depth of cure may be altered $(1,2)$. With respect to the organic matrix, the nature of the involved monomer molecules and the degree of conversion obtained in composite resin has an important effect upon mechanical properties (3), where the higher degrees of cure will improve the final properties of the material.
A higher degree of conversion can be obtained by using a high light intensity (4). However, this higher intensity may result in greater polymerization shrinkage and greater marginal leakage (5). Thus, new photoactivation techniques have been proposed, such as the programmed use of low and high intensities that have shown to be more effective in decreasing the stress generated by polymerization shrinkage, whilst maintaining a high degree of conversion and satisfactory mechanical properties (6-9). Since the introduction of this method, other photo-activation methods have been suggested including intermittent light $(9,10)$, plasma arc curing (PAC) (11) and, more recently, a new technology employing light-emitting diodes (LED) $(12,13)$. However, these innovative techniques require further investigation before they can be effectively applied in dental practice.

Thus, the aim of this study was to evaluate the

Correspondence: Dr. Mário Alexandre Coelho Sinhoreti, Faculdade de Odontologia de Piracicaba, UNICAMP, Av. Limeira 901, Bairro Areião, 13414-903 Piracicaba, SP, Brasil. Tel: +55-19-3412-5374; Fax: +55-19-3412-5218. e-mail: sinhoret@fop.unicamp.br 
depth of cure and Knoop hardness using different photoactivation methods.

\section{MATERIAL AND METHODS}

This study used the Filtek P60 composite resin (3M, St. Paul, MN, USA), shade A3. Composition and batch are reported in Table 1.

The composite was placed in a bipartite brass matrix that presented a central opening of $3 \mathrm{~mm}$ in diameter and $11 \mathrm{~mm}$ in height. The composite was then covered with a polyester strip and pressed with a glass slab to accommodate the material into the matrix. Photoactivation was performed with a) continuous light, b) exponential light, c) intermittent light, d) PAC, or e) LED. Five specimens were prepared for each photoactivation method.

For the continuous light photo-activation method, the curing tip was positioned close to the brass matrix/ restorative composite. The photo-activation was performed for $40 \mathrm{~s}$ with a high intensity of $800 \mathrm{~mW} / \mathrm{cm}^{2}$, using an Elipar Trilight curing unit (3M-ESPE, Seefeld, Germany). For the exponential light technique, the same curing unit was used, however, the light intensity began at zero, increasing gradually to $800 \mathrm{~mW} / \mathrm{cm}^{2}$, with a total exposure time of $40 \mathrm{~s}$. Curing with the intermittent light method was performed using a curing unit developed at the Dental Materials Department, School of Dentistry of Piracicaba, UNICAMP, which provided $2 \mathrm{~s}$ of light with an intensity of $600 \mathrm{~mW} / \mathrm{cm}^{2}$ and $2 \mathrm{~s}$ without light. The total exposure time was $80 \mathrm{~s}$. For the PAC technique, the Apollo $95 \mathrm{E}$ curing unit (DMD, Westlake, Village, CA, USA) was used which, according to the manufacturer's information, achieved an intensity of $1320 \mathrm{~mW} / \mathrm{cm}^{2}$. The light exposure time was 3 s. Finally, for the LED method, a LEC 4701 curing unit (MM Optics, São Carlos, SP, Brazil) was used to photo-activate the composite, providing an

Table 1. Composition and batch of the P60 composite resin.

\begin{tabular}{|c|c|}
\hline Organic matrix & BisGMA, UDMA, BisEMA, camphoroquinone \\
\hline Batch & $1 \mathrm{KY} 2004-04$ \\
\hline \multicolumn{2}{|l|}{ Filler } \\
\hline Type & Zirconia/silica \\
\hline$\%(\mathrm{vol})$ & 61 \\
\hline Size $(\mu \mathrm{m})$ & $0.19-3.3$ \\
\hline
\end{tabular}

intensity of $100 \mathrm{~mW} / \mathrm{cm}^{2}$ for $40 \mathrm{~s}$. The light intensity of the curing units was measured with a radiometer (Curing Radiometer, model 100, Demetron/Kerr, Danbury, CT, USA).

After photo-activation, the brass matrix was opened and all uncured material was removed using a steel spatula. The polymerized composite cylinder was measured using a digital pachymeter (Digital pachymeter, model CD-15C, Mitutoyo, Japan), which was positioned in the center of the specimen, determining the depth of cure.

The specimens were then included in self-curing acrylic resin (Artigos Odontológicos Clássico, São Paulo, SP, Brazil) and worn longitudinally along the center with 80 grit sandpaper (Carburundum Abrasivos, Recife, PE, Brazil) in a grinding wheel (Arotec, model APL-4, Cotia, SP, Brazil). Finishing and polishing were then performed with sandpaper of decreasing grits of 320, 400, 600 and 1000. After $24 \pm 1 \mathrm{~h}$, the Knoop hardness was measured at the surface and at depths of 1 , 2, 3, 4 and $5 \mathrm{~mm}$ with a Micro Hardness Tester (model HMV 2, Shimadzu, Japan), which was calibrated with a load of $50 \mathrm{~g}$ for $15 \mathrm{~s}$. Five readings were taken for each region and the arithmetic means were calculated for each region of the specimen.

The data were submitted to analysis of variance (ANOVA) and the means were compared by Tukey's test (significance level 5\%).

\section{RESULTS}

The results of the depth of cure and the Knoop hardness are presented in Tables 2 and 3, respectively. The intermittent light method had the highest depth of cure $(6.70 \mathrm{~mm})$ and was statistically different from the other methods $(\mathrm{p}<0.05)$. The continuous and exponential light techniques presented intermediate values and were statistically similar ( $p>0.05)$. The lowest depths of cure were obtained with the LED and the PAC methods. However, there were statistical differences between these, in which the LED demonstrated the lowest depth of cure.

Table 3 shows that up to a depth of $2 \mathrm{~mm}$, all photo-activation methods presented similar Knoop hardness values ( $p>0.05)$. At $3 \mathrm{~mm}$, the LED method presented the lowest value and the continuous light technique demonstrated an intermediate value and was statistically similar to the other methods. The intermit- 
tent, exponential and PAC methods revealed the highest values and with no statistical differences between them ( $\mathrm{p}>0.05)$.

At a depth of $4 \mathrm{~mm}$, the intermittent and continuous light methods presented the highest Knoop hardness values without significant differences between them ( $p>0.05$ ). Furthermore, the continuous light method demonstrated no difference from exponential light and PAC methods. LED revealed the lowest Knoop hardness value, which was significantly different from those of the other methods ( $\mathrm{p}<0.05$ ). At $5 \mathrm{~mm}$ depth, the LED and the PAC photo-activation methods could not be evaluated, as they did not reach this depth. At this depth, the continuous light method presented an intermediate value with no statistical difference from the other methods. The intermittent light method, however,

Table 2. Depth of cure according to photo-activation method.

\begin{tabular}{ll}
\hline Photo-activation method & Means \pm SD $(\mathrm{mm})$ \\
\hline Intermittent light & $6.70 \pm 0.26 \mathrm{a}$ \\
Continuous light & $6.08 \pm 0.18 \mathrm{~b}$ \\
Exponential light & $5.88 \pm 0.07 \mathrm{~b}$ \\
PAC & $4.67 \pm 0.12 \mathrm{c}$ \\
LED & $4.23 \pm 0.21 \mathrm{~d}$ \\
\hline
\end{tabular}

Means followed by different letters are statistically different at $5 \%$ by Tukey's test.

Table 3. Knoop hardness according to region and photo-activation method.

\begin{tabular}{|c|c|c|c|c|c|c|}
\hline Method & Surface & $1 \mathrm{~mm}$ & $2 \mathrm{~mm}$ & $3 \mathrm{~mm}$ & $4 \mathrm{~mm}$ & $5 \mathrm{~mm}$ \\
\hline Intermittent & $\begin{array}{l}103.65 \mathrm{a} \\
(11.28)\end{array}$ & $\begin{array}{c}105.20 \mathrm{a} \\
(7.11)\end{array}$ & $\begin{array}{c}104.08 \mathrm{a} \\
(7.82)\end{array}$ & $\begin{array}{c}101.43 \mathrm{a} \\
(5.55)\end{array}$ & $\begin{array}{l}95.30 \mathrm{a} \\
(3.52)\end{array}$ & $\begin{array}{c}80.15 \mathrm{a} \\
(4.16)\end{array}$ \\
\hline Continuous & $\begin{array}{c}103.65 \mathrm{a} \\
(5.58)\end{array}$ & $\begin{array}{c}103.15 \mathrm{a} \\
(5.39)\end{array}$ & $\begin{array}{l}99.59 \mathrm{a} \\
(6.31)\end{array}$ & $\begin{array}{c}91.80 \mathrm{ab} \\
(5.22)\end{array}$ & $\begin{array}{c}79.84 \mathrm{ab} \\
(5.81)\end{array}$ & $\begin{array}{c}66.15 \mathrm{ab} \\
(4.80)\end{array}$ \\
\hline Exponential & $\begin{array}{c}104.21 \mathrm{a} \\
(3.57)\end{array}$ & $\begin{array}{c}105.93 \mathrm{a} \\
(5.30)\end{array}$ & $\begin{array}{c}102.18 \mathrm{a} \\
(4.76)\end{array}$ & $\begin{array}{c}93.85 \mathrm{a} \\
(5.02)\end{array}$ & $\begin{array}{l}77.61 \mathrm{~b} \\
(8.97)\end{array}$ & $\begin{array}{l}54.96 \mathrm{~b} \\
(11.81)\end{array}$ \\
\hline PAC & $\begin{array}{c}108.22 \mathrm{a} \\
(5.72)\end{array}$ & $\begin{array}{c}107.89 a \\
(9.32)\end{array}$ & $\begin{array}{c}101.08 \mathrm{a} \\
(5.59)\end{array}$ & $\begin{array}{l}91.83 \mathrm{a} \\
(4.48)\end{array}$ & $\begin{array}{l}70.04 b \\
(6.55)\end{array}$ & $\begin{array}{c}0.00 \mathrm{c} \\
-\end{array}$ \\
\hline LED & $\begin{array}{c}114.88 \mathrm{a} \\
(10.22)\end{array}$ & $\begin{array}{c}111.90 \mathrm{a} \\
(9.96)\end{array}$ & $\begin{array}{c}101.59 \mathrm{a} \\
(9.29)\end{array}$ & $\begin{array}{l}78.93 b \\
(6.85)\end{array}$ & $\begin{array}{l}37.19 \mathrm{c} \\
(35.21)\end{array}$ & $\begin{array}{c}0.00 \mathrm{c} \\
-\end{array}$ \\
\hline
\end{tabular}

Means followed by different letters, in column, are statistically different at $5 \%$ by Tukey's test. Standard deviation is given within parentheses. revealed a statistically higher value than that of the exponential light method $(\mathrm{p}<0.05)$.

\section{DISCUSSION}

The development of new technologies for photoactivation of restorative composite resins has caused great interest among researchers (6-13). However, the real advantages of these techniques are not yet totally known. Before these methods can be clinically applied, the final properties of the photo-activated composites must be evaluated. Thus, this study evaluated the depth of cure and the Knoop hardness of the P60 composite resin, using different photo-activation methods.

The results of this study showed that the depth of cure is strongly affected by photo-activation methods. The intermittent light demonstrated the highest depth of cure $(6.70 \mathrm{~mm})$ and was statistically different from the other methods.

The intermittent, continuous and exponential light methods supply energy for photo-activation via halogen lamps, and the white light must be filtered to emit only the blue spectrum of the visible light. To generate blue light, the lamps must be heated to very high temperatures (14), resulting in the emission of heat through the curing light tip $(15,16)$. This heat transmission to the material may be, in part, responsible for the higher depth of cure values achieved using these methods, because the heat may increase the mobility of the monomers, increasing the probability of the occurrence of conversion.

Another factor that may have influenced the depth of cure and caused the difference between the intermittent light and the continuous and exponential methods is the total amount of energy supplied to the composite for the polymerization. According to Sakaguchi and Berge (8), maximum light intensity is achieved at $0.55 \mathrm{~s}$ and then decreases, signifying that, even with the continuous light method $\left(800 \mathrm{~mW} / \mathrm{cm}^{2}\right)$, the amount of energy supplied is not constant. Conversely, the intermittent light method employs $2 \mathrm{~s}$ of light exposure followed by $2 \mathrm{~s}$ without light, meaning that the maximum light intensity peak is achieved every time that the light is emit- 
ted. Since the polymerization process seems more dependent on the total energy available for photo-activation than the light intensity property $(8,17)$, this method may provide a higher amount of energy to the material, which may explain the higher depth of cure values achieved using the intermittent method.

The PAC method employs a different technology in which the light is produced by two electrodes that are placed very close to each other, emitting light when a high voltage is applied rather than by heating a tungsten filament as a halogen lamp (14). PAC curing light units generate heat and achieve very high light intensity $\left(1320 \mathrm{~mW} / \mathrm{cm}^{2}\right)$. However, the depth of cure value was lower than that obtained by methods that employ halogen lamps. This result may be due to the reduced photo-activation time used in PAC, representing a lower amount of energy $(8,17)$ and a short time period for the light to reach deeper regions of the material, since part of the light necessary for polymerization is absorbed and scattered by the already polymerized composite $(1,18)$. According to Peutzfeldt et al. (11), when curing light units are studied, an important parameter is the amount of light energy of appropriate wavelength emitted during irradiation. This energy is calculated as the product of the output of the curing light unit and the time of irradiation and may be termed as energy density. According to these authors, the Apollo $95 \mathrm{E}$ emits less energy in $3 \mathrm{~s}$ than do the conventional curing light units. This could explain the lower depth of cure obtained with this method when compared to methods that use the halogen lamp.

LED, the more recent technology developed for photo-activation of resinous materials, combines two different semiconductors ( $\mathrm{p}-\mathrm{n}$ junctions). When a voltage is applied, the electrons and 'holes' recombine at the LED's $\mathrm{p}-\mathrm{n}$ junctions leading, in the case of gallium nitride LEDs, to emission of blue light. The spectral output of gallium nitride blue LED falls conveniently within the absorption spectrum of the camphoroquinone photo-initiator $(400-500 \mathrm{~nm})$ presented in most light-activated composite resins, thus no filters are required in LED light curing units $(12,13)$. However, the LED demonstrated the lowest depth of cure. This result may be due to the low light intensity (100 $\mathrm{mW} / \mathrm{cm}^{2}$ ) and to the absence of heat emission with this curing light unit. Increasing the exposure time or the light intensity could minimize this problem.

The Knoop hardness test showed that, up to a depth of $2 \mathrm{~mm}$, all photo-activation methods provided similar values. This result demonstrates that despite the particular characteristics of each method, the light intensity and the exposure time were enough to adequately polymerize this thickness of composite.

At a depth of $3 \mathrm{~mm}$, the LED demonstrated the lowest hardness value, while the continuous light method revealed an intermediate value with no statistical difference from the other methods. The lower value observed with LED may be due to the low intensity produced by this technique. Even the LED method achieves the maximum irradiation at $466 \mathrm{~nm}$, which according to Nemoto (20) is the most efficient wavelength to excite camphoroquinone; however, the light is absorbed and/ or scattered when the thickness increases $(1,18)$, consequently decreasing the amount of energy for photoactivation. This fact may explain the lower hardness observed at $3 \mathrm{~mm}$ depth when LED was used. Despite this scattering and absorbance of light, all other methods supplied higher amounts of energy to the composite and, thus, provided higher hardness values at $3 \mathrm{~mm}$ depth.

At a depth of $4 \mathrm{~mm}$, the intermittent and continuous light methods demonstrated the highest hardness values without differences between them. The continuous light was similar to the exponential light and PAC, whilst the LED presented the lowest hardness, with statistical differences from the other methods. This result may be due to the total amount of energy that reached the material at this depth. The total energy is related to exposure time and light intensity generated by each method, i.e., the energy density $(1,4,8,11)$.

At a depth of $5 \mathrm{~mm}$, the LED and the PAC methods could not be evaluated since they did not achieve a depth of cure of $5 \mathrm{~mm}$. At this depth, the continuous light method presented an intermediate value and was no different from the intermittent and exponential methods. However, the intermittent light revealed a higher hardness value than the exponential technique. Again, the probable explication for this occurrence may be the total amount of energy supplied to the camphoroquinone, even at great depth. It seems that the intermittent method was able to provide a higher amount of energy at this depth, probably due to intermittence itself, where the maximum intensity is achieved at 0.55 $\mathrm{s}$ and then decreases (8).

Whilst all the photo-activation methods provided depth of cure values that fulfilled the require- 
ments of the ISO 4049 (19), there were differences observed between the methods at depths greater than 2 $\mathrm{mm}$. These differences were probably due to the characteristics of each method such as the light intensity, exposure time and heat generated. Therefore, in spite of the P60 composite manufacturer's claims of increments of $2.5 \mathrm{~mm}$, thickness greater than $2 \mathrm{~mm}$ should not be used clinically due to differences in the curing light units, possibly resulting in poorly polymerized material at deeper regions of the restoration $(1,4)$.

\section{RESUMO}

O objetivo deste trabalho foi avaliar a profundidade de polimerização e a dureza Knoop do compósito restaurador P60 fotoativado por diferentes métodos. Uma matriz metálica bipartida (3 mm de diâmetro X $11 \mathrm{~mm}$ de altura) foi preenchida com o compósito e fotoativada através da luz contínua, luz exponencial, luz intermitente, plasma de xenônio (PAC) ou luz emitida por diodo (LED). Após a abertura da matriz, o material não polimerizado foi removido com o auxílio de uma espátula metálica e o compósito polimerizado medido com um paquímetro digital. Então os espécimes foram incluídos em resina acrílica autopolimerizável e desgastados longitudinalmente e a dureza foi medida na superfície e nas profundidades de 1, 2, 3, 4 e $5 \mathrm{~mm}$. Os dados foram analisados por ANOVA e teste de Tukey (5\%). Os resultados mostraram que a profundidade de polimerização foi maior com a luz intermitente, seguida pela luz contínua, luz exponencial, PAC e LED. Até a profundidate de $2 \mathrm{~mm}$, todos os métodos de fotoativação revelaram valores de dureza similares, porém diferiram a outras profundidades, onde o LED demonstrou os menores valores, seguido pelo PAC.

\section{REFERENCES}

1. Rueggeberg FA, Caughman WF, Curtis Jr JW, Davis HC. Factors affecting cure at depths within light-activated resin composites. Am J Dent 1993;6:91-95.

2. Correr Sobrinho L, de Lima AA, Consani S, Sinhoreti MAC, Knowles JC. Influence of curing tip distance on composite Knoop hardness values. Braz Dent J 2000;11:11-17.

3. Lovell LG, Lu H, Elliott JE, Stansbury JW, Bowman CN. The effect of cure rate on the mechanical properties of dental resins.
Dent Mater 2001;17:504-511.

4. Rueggeberg FA, Caughman WF, Curtis Jr JW. Effect of light intensity and exposure duration on cure of resin composite. Operative Dent 1994;19:26-32.

5. Venhoven BAM, de Gee AJ, Davidson CL. Polymerization contraction and conversion of light curing Bis-GMA-based methacrylate resins. Biomaterials 1993;14:871-875.

6. Uno S, Asmussen E. Marginal adaptation of a restorative resin polymerized at reduced rate. Scand J Dent Res 1991;99:440-444.

7. Feilzer AJ, Doreen LH, de Gee AJ, Davidson CL. Influence of light intensity on polymerization shrinkage and integrity of restoration-cavity interface. Eur J Oral Sci 1995;103:322-326.

8. Sakaguchi RL, Berge HX. Reduced light energy density decreases post-gel contraction while maintaining degree of conversion in composites. J Dent 1998;26:695-700.

9. Obici AC, Sinhoreti MAC, de Goes MF, Simonides C, Sobrinho LC. Effect of the photo-activation method on polymerization shrinkage of restorative composites. Operative Dent 2002;27:192198.

10. Tarle Z, Meniga A, Ristic M, Sutalo J, Pichler G. The effect of the photopolymerization method on the quality of composite resin. J Oral Rehabil 1998;25:436-442.

11. Peutzfeldt A, Sahari A, Asmussen E. Characterization of resin composites polymerized with plasma arc curing units. Dent Mat 2000;16:330-336.

12. Jandt KD, Mills RW, Blackwell GB, Ashworth SH. Depth of cure and compressive strength of dental composites cured with blue light emitting diodes (LEDs). Dent Mater 2000;16:41-47.

13. Kurachi C, Tuboy AM, Magalhães DV, Bognato VS. Hardness evaluation of a dental composite polymerized with experimental LED-based devices. Dent Mater 2001;17:309-315.

14. 3M-ESPE. DentNet Masters - 3M ESPErtise Scientific - Elipar Freelight: Cordless LED curing unit. Seefeld, 2001.

15. Harrington E, Wilson HJ. Determination of radiation energy emitted by light activation units. J Oral Rehabil 1995;22:377-385.

16. Loney RW, Prince RB. Temperature transmission of high-output light-curing units through dentin. Operative Dent 2001;26:516520 .

17. Miyazaki M, Oshida Y, Moore BK, Onose H. Effect of light exposure on fracture toughness and flexural strength of lightcured composites. Dent Mater 1996;12:328-332.

18. Baharav H, Abraham D, Cardash HS, Helft M. Effect of exposure time on the depth of polymerization of a visible light-cured composite resin. J Oral Rehabil 1988;15:167-172.

19. International Organization for Standardization. ISO 4049 - Dentistry - Polymer-based filling, restorative and luting materials. Switzerland, 2000. 27f.

20. Nemoto R. Effect of light wavelength on polymerization of lightcured resins. Dent Mater J 1997;16:60-73. 